\title{
Systemic mastocytosis with flushing and hypotension: A case report and literature review
}

\author{
AN-TIAN CHEN ${ }^{1 *}$, XIN-YU REN ${ }^{2 *}$ and WEI CHEN ${ }^{1}$ \\ Departments of ${ }^{1}$ Cardiology and ${ }^{2}$ Pathology, Peking Union Medical College Hospital, \\ Chinese Academy of Medical Sciences and Peking Union Medical College, Beijing 100730, P.R. China
}

Received April 13, 2020; Accepted August 19, 2020

DOI: $10.3892 /$ etm.2021.9835

\begin{abstract}
Systemic mastocytosis (SM) is a heterogeneous disease of the bone marrow, which is characterized by the abnormal proliferation and infiltration of mast cells in one or more organs, such as the skin, bone marrow, digestive tract, liver and spleen. Urticaria pigmentosa is a typical but infrequent manifestation of SM. Other clinical presentations are non-specific, varying from pruritus and hypotension to multiple organ dysfunction, which may be lethal when hemodynamic changes occur, such as the sharp decline in blood pressure observed in the present case. In patients who lack skin lesions, the diagnosis of SM is frequently challenging. The present study reported on a 58-year-old male who presented with episodic flushing and syncope. The patient demonstrated marked neutrophilia and reduced blood potassium concentrations soon after the onset of each episode, which was able to last several hours, ranging from once to four times a year. SM without skin lesions was suspected and confirmed after multifocal bone marrow aspiration, which revealed dense infiltrates of mast cells ( $\geq 15$ mast cells), with positive toluidine blue and CD117 staining. The present case illustrates the significance of taking SM or mast cell activation syndrome into consideration when unexplained recurrent hypotension or even syncope are observed, care should be taken to exclude differential diagnoses, as some of them may have much poorer prognoses and require alternative treatments.
\end{abstract}

\section{Introduction}

Systemic mastocytosis (SM) is a heterogeneous disease of the bone marrow characterized by the abnormal proliferation and

Correspondence to: Dr Wei Chen, Department of Cardiology, Peking Union Medical College Hospital, Chinese Academy of Medical Sciences and Peking Union Medical College, 1 Shuaifuyuan, Beijing 100730, P.R. China

E-mail: chenwei6@medmail.com.cn

*Contributed equally

Key words: systemic mastocytosis, mast cell activation syndrome, hypotension, flushing, bone marrow biopsy, pathology infiltration of mast cells in various organs and systems (1). SM is not common and has been reported with an incidence of 13 in 100,000 people; however, the real prevalence may be higher because of underdiagnosis (2). The clinical manifestations are associated with the acute release of diverse mast cell mediators, such as histamine, heparin, eosinophil chemotactic factor, slow reaction substance and 5-hydroxytryptamine (5-HT). The symptoms include pruritus, episodic flushing, syncope, gastrointestinal symptoms, musculoskeletal pain and neuropsychiatric disorders. However, mast cell activation syndrome (MCAS) refers to a range of disorders characterized by accumulated mast cells and/or the abnormal release of mediators inside these cells, which seldom causes abnormalities in routine laboratory parameters or imaging examinations $(3,4)$. Bone marrow biopsy and immunohistochemical analysis of the specimen may contribute to the classification of SM or MCAS. Skin lesions, such as urticaria pigmentosa, are among the classical presentations of mastocytosis (1). In patients without skin lesions, mastocytosis is frequently misdiagnosed as another disease, such as anaphylaxis, or may even remain unidentified. In individuals presenting with mast cell mediator release symptoms, mastocytosis should be suspected, and serum tryptase levels, bone marrow smear and biopsy may help to diagnose the condition (1). The present study reported on a case of SM, which may increase the awareness of clinicians of this disease.

\section{Case report}

Acute chief complaints and history of SM. A 58-year-old male presented with recurrent flushing, hypotension and loss of consciousness, the severity of which varied, was admitted to the Department of Cardiology in September 2013 to obtain a diagnosis. The patient's symptoms started when he was 46 years old and notably included recurrent episodes of flushing, hypotension and unconsciousness.

Medical history. The patient had a 19-year history of hypertension, with a blood pressure that rose to as high as $160 / 110 \mathrm{mmHg}$ but had been controlled at $\sim 130 / 90 \mathrm{mmHg}$ for years.

Medication history. The pre-admission medications included indapamide tablets ( $2.5 \mathrm{mg}$ once a day) and metoprolol tartrate tablets (25 mg every $12 \mathrm{~h}$ ). 
Physical examination. There was no significant change in blood pressure when the patient moved from recumbent to orthostatic positions. Cardiorespiratory and abdominal physical examinations were negative. There was also no swelling in either lower extremity.

Episode prior to admission. The patient had a 12-year history of recurrent facial, anterior chest and skin flush with bulbar conjunctival congestion, and experienced stuffy nose, as well as discomfort in the chest and upper abdomen, but did not present with associated chest pain, dyspnea or fever. The patient's blood pressure declined 1-2 $\mathrm{h}$ after the onset of each episode to 70-90 $\mathrm{mmHg}$ systolic with skin flush, which was able to recover to $120 / 80 \mathrm{mmHg}$ without treatment after several hours. A temporary loss of consciousness was observed during several severe onsets, with a minimum systolic blood pressure of 20-30 mmHg. Vasoactive medications, such as dopamine and noradrenaline, were administered to maintain blood pressure. Following treatment, the skin flush and bulbar conjunctival hyperemia were gradually be relieved. Vasoactive medications were discontinued after several hours to two days depending on the severity of each attack. The frequency of the aforementioned symptoms varied from once to four times yearly, with similar symptoms but to different extents. There was no apparent association between the attacks and the season, time of day or night, region of stay or diet. The onset was also not associated with the patient being in an active, resting, sleeping, standing or recumbent state.

An episode during hospitalization. On the day after admission, there was a new onset with no stimulus. The patient presented with bulbar conjunctival congestion, flush of the face and anterior chest skin, as well as nasal congestion. After $\sim 1 \mathrm{~h}$, the patient's blood pressure began to decline. Intensive care and fluid infusion therapy were started, but the blood pressure still dropped to a minimum of $72 / 43 \mathrm{mmHg} \sim 2 \mathrm{~h}$ after the beginning of the attack and then gradually increased. The redness of the skin was also relieved as the blood pressure increased. There was no unconsciousness, diarrhea, itching or dyspnea during the onset; however, the patient had no complete recollection of the time of the episode.

Laboratory examinations. The leukocyte $\left(13.53 \times 10^{9} / 1\right)$ and neutrophil $\left(11.22 \times 10^{9} / 1\right)$ concentrations exhibited marked increases during the attack and blood potassium was decreased (3.3 $\mathrm{mmol} / \mathrm{l}$; normal range 3.5-5.5 $\mathrm{mmol} / \mathrm{l}$ ), while the hemoglobin and platelet counts were normal. Following the attack, the complete blood count and blood potassium spontaneously returned to the normal range (Fig. 1). Laboratory tests of the liver and renal function and arterial blood gas were also within normal limits. No abnormalities were found in the erythrocyte sedimentation rate, $\mathrm{C}$-reactive protein and complement $\mathrm{C} 3$ and $\mathrm{C} 4$.

Antinuclear antibodies, anti-double-stranded DNA, anti-soluble nuclear antigen antibodies and tumor markers were all negative. Plasma protein gel electrophoresis, blood immuno-fixation electrophoresis, test of thyroid function, three repeated tests of levels of calcitonin and 24-h urinary catecholamine examinations were also negative.

The head-up tilt test was positive with nitroglycerin. Serum total immunoglobulin E (IgE) was $90 \mathrm{KU} / 1$ (normal,
0-60 KU/1). Inhalant/food/mold allergen, anti-C1Q antibody and $\mathrm{C} 1$ inhibitor tests were negative. Serum tryptase was $81.6 \mathrm{ng} / \mathrm{ml}$ during onset, decreased to $36.3 \mathrm{ng} / \mathrm{ml} 9$ days later and remained at $9.85 \mathrm{ng} / \mathrm{ml}$ (normal, $0-13.0 \mathrm{ng} / \mathrm{ml}$ ) on the 16th day (Fig. 1).

Imaging examinations. Electrocardiogram (ECG), neck vascular ultrasound (CVUS), transcranial doppler ultrasound (TCD), cerebral MRI angiography, thyroid ultrasound, echocardiography, octreotide imaging, gastroenteroscopy, contrast-enhanced CT scans of the chest, abdomen and pelvis, and positron emission tomography/CT of the chest, abdomen and pelvis were all unremarkable.

Pathological examination. The peripheral blood smears both during the onsets and remission were all negative. Multifocal bone marrow smear (posterior ilium/anterior iliac/sternum) exhibited active proliferation and phagocytic cells were observed. The percentage of basophils in certain tissues was up to $0.5 \%$ and clusters of basophils were observed. The pathology of the bone marrow biopsy (posterior ilium) was as follows: Megakaryocytes were identified and mast cell infiltration existed, which supported the diagnosis of SM. Mast cell-specific staining was then performed; methylaniline blue staining was positive but scattered. Immunohistochemistry revealed positive staining for CD117 (mast cells ++), CD15 (granulocytes +), myeloperoxidase (granulocytes + ) and CD20 (diffuse + ), and negative staining for CD3 (Fig. 2). Tests for the cKIT/D816V and factor interacting with poly(A) polymerase $\alpha$ and cleavage and polyadenylation-specific factor $1 /$ platelet-derived growth factor receptor $\alpha$ (FIP1L1/PDGFR $\alpha$ ) gene mutations in bone marrow were negative.

Mast cells infiltrated in the bone marrow pathology (CD117; Fig. 2) were further counted and the result suggested $a \geq 15$ mast cell aggregation in the field of view and multifocality, consistent with the major diagnostic criteria for SM (1).

Final diagnosis. The final diagnosis of the present case was inert SM, MCAS and increased excitability of the vasovagal nerve, all of which contributed to the flushing and hypotension status in the present case.

Treatment. The patient refused to use glucocorticosteroids and medications to control the mast cell mediator release symptoms. As an alternative, an adrenaline pen was carried as a backup. Metoprolol was prescribed prior to admission due to hypertension and was not recommended following discharge, since it may make the adrenergic response less effective.

Outcome and follow-up. The patient was followed up for 4 years by telephone and no further onset was observed. The patient did not undergo any tests of serum tryptase or bone marrow puncture after discharge from our hospital.

\section{Discussion}

The present case was that of a middle-aged male with a 12-year history of episodes of recurrent flushing, hypotension and loss of consciousness. The characteristics of the symptoms were as follows: i) No obvious stimulus of each onset, 

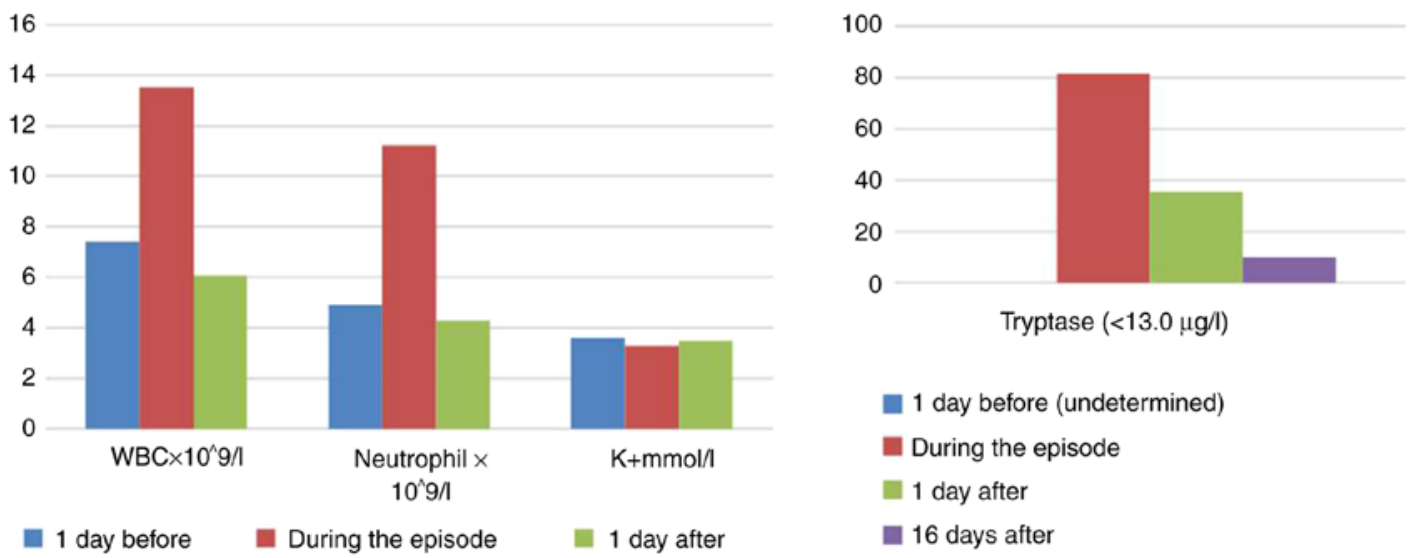

Figure 1. Changes in the WBC count, potassium and tryptase prior to, during and after the episodic period of the patient. Normal ranges: WBC, 3.50-9.50x10 $/ 1$; Neutrophil, 2.00-7.50x10\%/1; $\mathrm{K}^{+}, 3.5-5.5 \mathrm{mmol} / 1$; and Tryptase, $<13.0 \mu \mathrm{g} / \mathrm{l}$. WBC, white blood cell.
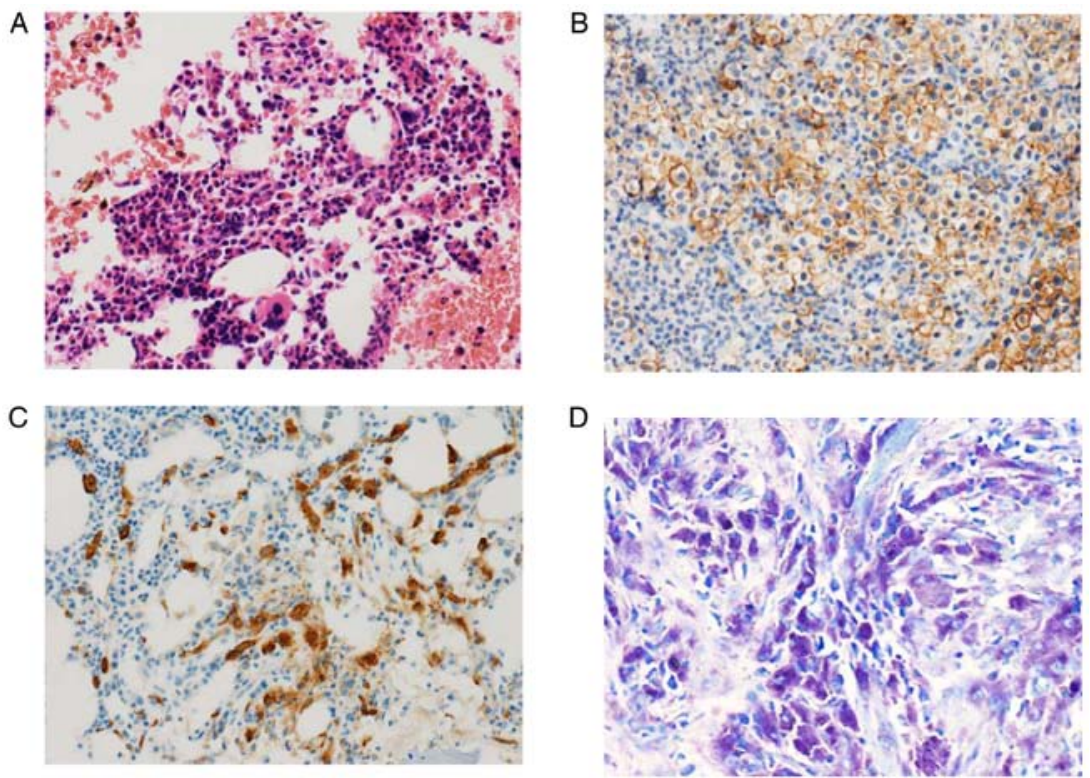

Figure 2. Histological analysis of the bone marrow. (A) Mast cells on bone marrow aspirate (H\&E). (B) Mast cells were positive for CD25 (IHC). (C) Mast cells were strongly positive for CD117 (IHC). (D) Mast cells detected by methylaniline blue staining. Magnification, x10. IHC, immunohistochemistry.

no association with diet, climate, exercise or body position, and in the interictal period, the patient was completely normal; ii) facial and anterior chest skin flush together with bulbar conjunctival hyperemia were initially observed, followed by a drop of blood pressure, increase in leukocytes and decrease in blood potassium, whereas the heart rate and rhythm were basically normal; iii) temporary loss of consciousness during the episode; for mild episodes, recovery may be self-sustained; iv) short-term fluid replacement and pressor support therapy were required when the episode was severe; v) reduced memory capacity after onset.

Regarding the diagnosis, the patient had transient loss of consciousness during the onset, making it necessary to rule out the possibility of epilepsy and transient ischemic attack (TIA) caused by cerebrovascular disease (5). The prodromal symptoms in this case, including redness of the skin and hyperemia of the conjunctiva, are not common symptoms of epilepsy. BP is normal or even high rather than low in epileptic seizure. The EEG of the present patient showed no abnormal brain activity during an attack aiding the differentiation of syncope from epileptic (6). With regard to cerebrovascular disease, there were no major risk factors of cerebrovascular disease found in this patient and no abnormality was observed in the intracranial and extracranial blood vessels using CVUS, TCD and cerebral MRI angiography. As episodic and transient loss of consciousness occurred in this case, the diagnosis of syncope should be considered.

There are three types of syncope with different presentations: Postural hypotension, cardiac syncope and reflex syncope (5). The onset of each episode for the patient of the present study was not associated with postural changes, and the change in blood pressure from a recumbent to an orthostatic position was not significant, which make the condition less likely to be postural hypotension. Cardiogenic syncope may be caused by obstructive and ischemic disorders, arrhythmia, pulmonary and pericardial diseases (6). However, normal results of the ECG, ECHO, coronary angiography, pulmonary $\mathrm{CT}$ and arterial blood gas analysis during and after the attack 
render cardiogenic syncope highly unlikely. While in patients with reflex syncope episodes, prodromal symptoms, such as dizziness, panic and weakness are common, which did not appear in this patient. Although the orthostatic tilt test was positive after nitroglycerin induction, the syncope induced by the test was not accompanied by redness of the skin and hyperemia of the bulbar conjunctiva. It remains challenging to explain the full clinical picture of the patient by increased excitability of the vasovagal nerve, which could only explain hypotension but would not be responsible for elevated serum tryptase levels.

One notable symptom of the patient of the present study was that the skin flush prior to each onset, except when syncope was accompanied by a marked drop in blood pressure in parallel during the onset. Therefore, flush and hypotension were the principal clinical characteristics of the patient. Murali et al (7) provided a comprehensive list summarizing disorders for differential diagnosis of patients with flushing and hypotension, including exogenous and endogenous factors. Exogenous factors, such as diet and medication, may give rise to severe allergic reactions that frequently lead to recurrent skin flushing, hypotension and shock. Slightly elevated $\operatorname{IgE}$ and clinical symptoms suggest a possibility of allergy (8). However, allergens and the association between the onset of symptoms and diet, medication and contactors were all absent, and no seasonal or geographical patterns were identified for the attacks. Therefore, exogenous factors are less likely to cause this situation.

Possible endogenous factors include sepsis, carcinoid syndrome, endocrine tumor, idiopathic capillary leakage syndrome and mastocytosis (5). First, the present patient maintained a normal body temperature during the attack and the hypotension was transient and at times completely self-limited, which bears no support for sepsis. Furthermore, carcinoid syndrome refers to a group of argyrophilic cell tumors occurring in the gastrointestinal tract or other organs (e.g. lung, pancreas, ovary) that is able to secrete 5-HT, bradykinin and histamine, which may lead to skin flush, abdominal pain, diarrhea, hypotension, wheeze attacks and even heart valve disease (9). The present patient had no gastrointestinal or respiratory symptoms, and gastroenteroscopy, octreotide imaging and contrast-enhanced CT of the chest and abdomen were all unremarkable. Thus, the probability of carcinoid was low. Endocrine tumors, such as pheochromocytoma, may also lead to hypotension. However, pheochromocytoma is not accompanied by skin flushing. The thyroid ultrasound did not display any lesions in this case; thus, no support for medullary thyroid carcinoma was identified. In addition, no symptoms of paroxysmal diarrhea were presented, and no occupation lesions of the pancreas were observed, and thus, vasoactive intestinal peptide tumors were not a possible diagnosis. As for idiopathic capillary leakage syndrome, this is characterized by hypotension, hypoalbuminemia and hemoconcentration, and is frequently induced by factors such as upper respiratory tract infection (10). The initial onset is distributed shock symptoms, such as warm skin and flush; however, the patient of the present study exhibited no hypoalbuminemia and hemoconcentration, which is inconsistent with this diagnosis. The last endogenous factor to consider is mastocytosis. The patient had a significantly higher tryptase level, which was $>20 \mathrm{ng} / \mathrm{ml}$ at the time of the attack, and multiple focal mast cell infiltration ( $\geq 15$ mast cell aggregation in the field of view) was observed in the bone marrow biopsy, which supports the diagnosis of SM.

SM belongs to a group of mast cell monoclonal proliferative diseases under the umbrella term of mast cell hyperplasia, which was first reported by Ellis (11) in 1949. In 2016, the World Health Organization divided mast cell hyperplasia into three categories, including skin type, SM and mast cell sarcoma (12). The diagnostic criteria for SM include one major criterion and four minor criteria. The major criterion is multifocal dense mast-cell infiltration ( $\geq 15$ mast cell aggregation in the field of view) in the bone marrow and/or other nonskin tissue sections (12). The minor criteria are as follows: i) $>25 \%$ spindle or atypical mast cell infiltration in non-skin tissue sections or bone marrow smears or $>25 \%$ mast cell are immature or atypical; ii) mutations in codon 816 of the KIT gene detected in bone marrow, blood or other non-skin tissues; iii) mast cells in bone marrow, blood or other non-skin tissues express CD25 with/without CD2 in addition to normal mast cell markers; and iv) serum tryptase levels $>20 \mathrm{ng} / \mathrm{ml}$ (unless an associated myeloid neoplasm exists that invalidates this parameter) (12). SM may be diagnosed when the primary criterion and one minor criterion, or three minor criteria, are fulfilled (1).

SM is further divided into several types according to the $\mathrm{B}$ and $\mathrm{C}$ findings (1). B findings include: i) Bone marrow biopsy reveals $>30 \%$ infiltration of mast cells in the field of view and serum tryptase level $>200 \mathrm{ng} / \mathrm{ml}$; ii) non-mast cell lineage dysplasia or myeloproliferation, but cannot meet the criteria to diagnose an associated hematological neoplasm (AHN), the blood counts are normal or slightly abnormal; and iii) Hepatomegaly and palpable splenomegaly withoutfunctional abnormality, and/or palpation or imaging lymphadenopathy. $\mathrm{C}$ findings include: i) Bone marrow dysfunction revealed by $\geq 1$ cytopenia(s) (absolute neutrophil count $<1.0 \times 109 / 1, \mathrm{Hgb}$ $<100 \mathrm{~g} / \mathrm{l}$, and/or platelet count $<100 \times 109 / 1$ ), which is caused by mast cell infiltration; ii) Palpable hepatomegaly with liver dysfunction, ascites and/or portal hypertension. iii) Skeletal involvement with large osteolytic lesions with/without pathological fractures (excluding fractures caused by osteoporosis); iv) Palpable splenomegaly with hypersplenism; v) Weight loss as a result of malabsorption due to mast cell infiltration in gastrointestinal system.

It is worth noting that conceptually, MCAS is frequently confused with mastocytosis. The diagnosis of MCAS should be made based on the following criteria: i) The clinical symptoms are caused by the release of mast cell mediators; ii) compared with the baseline value, serum tryptase increases by $>20 \%$ or the absolute value is increased by $>2 \mathrm{ng} / \mathrm{ml}$; and iii) anti-inflammatory mediator therapy (e.g. histamine receptor antagonists) is effective $(3,4)$. Symptoms of mast cell mediator release include redness and itching of the skin, heart palpitation, chest tightness, hypotension when the condition affects the circulatory system, gastrointestinal manifestations, such as paroxysmal abdominal pain, diarrhea, nausea and vomiting, nervous system symptoms, such as headache, convulsions and syncope, and other presentations, such as stuffy nose and larynx edema $(4,13)$. Depending on the cause, MCAS may be further divided into three categories: Primary (with monoclonal hyperplasia), secondary (secondary to 
Table I. Subtypes of SM.

Subtype of SM

Cutaneous mastocytosis

Indolent $\mathrm{SM}^{\mathrm{a}}$

Smoldering $\mathrm{SM}^{\mathrm{a}}$

SM with associated hematological neoplasm Aggressive $\mathrm{SM}^{\mathrm{a}}$

MCL
Definition

Urticaria pigmentosa/maculopapular cutaneous mastocytosis; diffuse cutaneous mastocytosis; solitary mastocytoma of skin

No 'C' findings. No evidence of associated hematological neoplasm

No ' $\mathrm{C}$ ' findings but with 2 or more ' $\mathrm{B}$ ' findings. No evidence of associated clonal hematological nonmast cell lineage disease

Evidence of associated clonal hematological nonmast cell lineage disease

1 or more ' $\mathrm{C}$ ' findings. No evidence of MCL

Bone marrow biopsy indicates a diffuse infiltration by atypical or immature mast cells. Bone marrow aspirate smears contain $\geq 20 \%$ mast cells. In typical MCL, mast cells account for $\geq 10 \%$ of the peripheral blood white cells. There is also an aleukemic MCL variant $(<10 \%$ circulating mast cells)

${ }^{\mathrm{a}}$ Information of B and C findings is required for further diagnosis of these subtypes. SM, systemic mastocytosis; MCL, mast cell leukemia.

total IgE-mediated allergy, inflammatory response, etc.) and idiopathic (no primary or secondary factors) $(3,4)$. The diagnostic criteria for MCAS are focused on the concentration of the mediators after mast cell activation and the symptoms caused by the release and response to treatment. However, the diagnosis of mastocytosis, particularly SM, focuses on the monoclonal proliferation of mast cells. There is a certain overlap between these two diseases. Mastocytosis also belongs to primary MCAS when symptoms of the release of mast cell mediators exist (4). The diagnosis of the present case also falls into the category of primary MCAS.

The etiology of SM remains to be fully established, and according to the literature, it is frequently associated with a functional acquired mutation of the KIT gene. KIT (CD117) is a type III tyrosine kinase receptor expressed in mast cells, and a mutation in this gene may induce the clonal proliferation of mast cells, without the control of hematopoietic stem cell factor $(14,15)$. The most common mutation site is D816V $(>80 \%)(14,15)$. Other causes, such as a tet methylcytosine dioxygenase 2 mutation, increased levels of hematopoietic stem cell factors and the persistent expression of heat shock protein 32 , may also be associated with the pathogenesis of $\operatorname{SM}(16,17)$.

In addition to mast cell mediator release syndrome, the infiltration of viscera by mast cells may occur in SM. Skin involvement may present urticaria and result in the formation of skin mastocytoma (1). Anemia, thrombocytopenia, enlargement of the liver and spleen or lymph nodes, portal hypertension, osteoporosis and pathological fracture may occur when there are endocrine manifestations, osteoporosis and osteosclerosis $(18,19)$. According to the presence or absence of type B or C features, SM may be further divided into seven subtypes (1) (Table I): Cutaneous mastocytosis, indolent SM (ISM), smoldering SM, SM with an associated hematological neoplasm (SM-AHN), aggressive SM (ASM), mast cell leukemia (MCL) and mast cell sarcoma $(12,15)$. In the present case, there was no evidence of type $\mathrm{B}$ or $\mathrm{C}$ features and no hematological malignancy, and mast cell lineages were identified; therefore, the present case may be classified as ISM. Elevated levels of serum tryptase, which is one of the mediators of mast cell release, are common in various SM subtypes (1). The peak is reached 15-60 min after the onset of symptoms and then gradually decreases, with a half-life of $\sim 2 \mathrm{~h}$ (4). This procedure has been recognized as one of the diagnostic criteria of SM and MCAS. The levels of serum tryptase in patients with ASM and SM-AHN are higher compared with ISM, and compared with ISM, these two subtypes also have a higher proportion of patients with serum tryptase levels $>200 \mathrm{ng} / \mathrm{ml}$ (20). Certain studies have suggested that serum tryptase levels are parallel to the infiltration of bone marrow mast cells in patients with ISM, but there is a poor correlation between the level of serum tryptase and the clinical symptoms of mast cell mediator release (21). Of note, in the present case, white blood cells were significantly elevated during the onset, mainly neutrophilic granulocytes, and decreased plasma potassium levels were detected (Fig. 1), all of which recovered spontaneously after remission, which is consistent with the literature (7). The pro-inflammatory and chemotactic factors released by mast cells may affect leukocyte migration and recruitment, but the decrease in serum potassium may be related to the redistribution of intracellular and extracellular potassium ions $(4,22)$.

As there is currently no cure for SM, current treatments focus on methods to control the symptoms, improve the quality of life and delay disease progression. The present treatments exhibit a marked variation depending on the subtype of SM. For patients with ISM, the major treatments are avoidance of the induction of mast cell release, control of the release symptoms of mast cells and local surgery (15). Drugs that are able to control the symptoms include antihistamines, including $\mathrm{H} 1$ or $\mathrm{H} 2$ receptor blockers, such as cetirizine and ranitidine, mast cell membrane stabilizers, such as sodium tryptophan, leukotriene inhibitors, such as montelukast, and nonsteroidal anti-inflammatory drugs (23). If the symptoms cause hypotension or shock, the first choice is adrenaline treatment, and glucocorticoid treatment is optional (24). In certain cases, shock was reported as a symptom but more frequently defined as anaphylactic shock (25-27). Other drugs, such as midostaurin and masitinib, have undergone phase 2 or 3 trials and still require further evaluation $(28,29)$. ASM 
should be treated with chemotherapy. Commonly used regimens include interferon- $\alpha$ alone or in combination with prednisone, or kratobine alone (15). In addition, tyrosine kinase inhibitors (TKIs), including imatinib, dashatinib and midostaurin, hydroxyurea and mitoxaline, may also be used, among which imatinib is the only drug approved by the US Food and Drug Administration for SM and is suitable for patients with SM with KIT mutations that are sensitive to imatinib or those without KIT D816V mutations (15). Over $80 \%$ of adults with mastocytosis carry this mutation (30-32). Midostaurin is the only TKI approved as a monotherapy for ASM (33). Hematopoietic stem cell transplantation has been reported to improve the survival rate among patients with SM $(34,35)$, but this requires to be confirmed by larger studies.

The prognosis of different subtypes of SM is significantly different from that of indolent life-threatening diseases (36). The prognosis of ISM is relatively good, with a median survival time of 198 months, which exhibits no significant difference between patients with ISM and healthy controls. The progression and prognosis of ISM are not associated with the ultrasonography findings (37). ASM and SM-AHN are associated with poor prognosis, with median survival rates of 41 and 24 months, respectively. By contrast, MCL has a dismal prognosis, with a median survival time of only 2 months (15). The patient in the present study belonged to the ISM group, and hematology specialists in the Peking Union Medical College Hospital recommended two treatment options for the patient. The first was using drugs to control the release of mast cell mediators together with epinephrine and glucocorticoid treatment when the symptoms are severe. Another consideration is that this patient suffered a significant decline in blood pressure during the onset of symptoms, which may lead to a lack of blood supply to vital organs and potentially fatal arrhythmia. Therefore, it was recommended that the patient begins treatment with interferon and/or glucocorticoid immediately. However, the patient did not accept the aforementioned scheme due to the potential side effects of the medications, and he purchased and carried an adrenalin pen as a precaution.

In conclusion, the diagnosis and treatment of the present case were in accordance with SM/MCAS. To date, this disease has been rarely reported, with high rates of missed diagnosis and misdiagnosis. Therefore, the understanding of this disease should be expanded. In addition to detection of postural hypotension, and cardiac and vascular factors in syncope patients, the possibility of SM/MCAS should be taken into consideration when encountering symptoms such as redness of the skin and severe hypotension. Bone marrow or histopathological examination, mast cell-specific and immunohistochemical staining, KIT gene detection and serum tryptase determination are of great significance in the diagnosis of SM/MCAS.

\section{Acknowledgements}

The authors wish to thank Dr Haiyan He (Department of Cardiology, Peking Union Medical College Hospital) for her help in preparing and editing this manuscript.

\section{Funding}

No funding was received.

\section{Availability of data and materials}

The datasets used and/or analyzed during the current study are available from the corresponding author on reasonable request.

\section{Authors' contributions}

ATC performed the literature search/selection/review and collected clinical information and drafted the manuscript. XYR provided critical pathological reports and diagnostic consulting services. ATC and XYR contributed equally to this study. WC conceived the study and revised the manuscript. All authors read and approved the final manuscript.

\section{Ethics approval and consent to participate}

Not applicable.

\section{Patient consent for publication}

Consent for publication of the patient's data/images in this case report was obtained.

\section{Competing interests}

The authors declare that they have no competing interests.

\section{References}

1. Pardanani A: Systemic mastocytosis in adults: 2019 update on diagnosis, risk stratification and management. Am J Hematol 94: 363-377, 2019.

2. Brockow K: Epidemiology, prognosis, and risk factors in mastocytosis. Immunol Allergy Clin North Am 34: 283-295, 2014.

3. Valent P: Mast cell activation syndromes: Definition and classification. Allergy 68: 417-424, 2013.

4. Valent P, Akin C,Arock M, Brockow K, Butterfield JH, Carter MC, Castells M, Escribano L, Hartmann K, Lieberman P, et al: Definitions, criteria and global classification of mast cell disorders with special reference to mast cell activation syndromes: A consensus proposal. Int Arch Allergy Immunol 157: 215-225, 2012.

5. Runser LA, Gauer RL and Houser A: Syncope: Evaluation and differential diagnosis. Am Fam Physician 95: 303-312, 2017.

6. Brignole M, Moya A, de Lange FJ, Deharo JC, Elliott PM, Fanciulli A, Fedorowski A, Furlan R, Kenny RA, Martín A, et al: 2018 ESC Guidelines for the diagnosis and management of syncope. Eur Heart J 39: 1883-1948, 2018.

7. Murali MR, Castells MC, Song JY, Dudzinski DM and Hasserjian RP: Case records of the Massachusetts General Hospital. Case 9-2011. A 37-year-old man with flushing and hypotension. N Engl J Med 364: 1155-1165, 2011.

8. Campbell DE and Mehr S: Fifty years of allergy: 1965-2015. J Paediatr Child Health 51: 91-93, 2015.

9. Rubin de Celis Ferrari AC, Glasberg J and Riechelmann RP: Carcinoid syndrome: Update on the pathophysiology and treatment. Clinics (Sao Paulo) 73 (Suppl 1): e490s, 2018.

10. Siddall E, Khatri M and Radhakrishnan J: Capillary leak syndrome: Etiologies, pathophysiology, and management. Kidney Int 92: 37-46, 2017.

11. Ellis JM: Urticaria pigmentosa; a report of a case with autopsy. Arch Pathol (Chic) 48: 426-435, 1949.

12. Arber DA, Orazi A, Hasserjian R, Thiele J, Borowitz MJ, Le Beau MM, Bloomfield CD, Cazzola M and Vardiman JW: The 2016 revision to the World Health Organization classification of myeloid neoplasms and acute leukemia. Blood 127: 2391-2405, 2016.

13. Metcalfe DD: Mast cells and mastocytosis. Blood 112: 946-956, 2008. 
14. Arock M, Sotlar K, Akin C, Broesby-Olsen S, Hoermann G, Escribano L, Kristensen TK, Kluin-Nelemans HC, Hermine O, Dubreuil P, et al: KIT mutation analysis in mast cell neoplasms: Recommendations of the European Competence Network on Mastocytosis. Leukemia 29: 1223-1232, 2015.

15. Pardanani A: Systemic mastocytosis in adults: 2017 update on diagnosis, risk stratification and management. Am J Hematol 91: 1146-1159, 2016.

16. Kondo R, Gleixner KV, Mayerhofer M, Vales A, Gruze A, Samorapoompichit P, Greish K, Krauth MT, Aichberger KJ, Pickl WF, et al: Identification of heat shock protein 32 (Hsp32) as a novel survival factor and therapeutic target in neoplastic mast cells. Blood 110: 661-669, 2007.

17. Tefferi A, Lim KH, Abdel-Wahab O, Lasho TL, Patel J, Patnaik MM, Hanson CA, Pardanani A, Gilliland DG and Levine RL: Detection of mutant TET2 in myeloid malignancies other than myeloproliferative neoplasms: CMML, MDS, MDS/MPN and AML. Leukemia 23: 1343-1345, 2009.

18. Greene LW, Asadipooya K, Corradi PF and Akin C: Endocrine manifestations of systemic mastocytosis in bone. Rev Endocr Metab Disord 17: 419-431, 2016.

19. Johansson C, Roupe G, Lindstedt G and Mellstrom D: Bone density, bone markers and bone radiological features in mastocytosis. Age and ageing 25: 1-7, 1996.

20. Lim KH, Tefferi A, Lasho TL, Finke C, Patnaik M, Butterfield JH, McClure RF, Li CY and Pardanani A: Systemic mastocytosis in 342 consecutive adults: Survival studies and prognostic factors Blood 113: 5727-5736, 2009.

21. Pardanani A, Lim KH, Lasho TL, Finke CM, McClure RF, Li CY and Tefferi A: WHO subvariants of indolent mastocytosis: Clinical details and prognostic evaluation in 159 consecutive adults. Blood 115: 150-151, 2010.

22. Valent P, Sillaber C, Baghestanian M, Bankl HC, Kiener HP, Lechner K and Binder BR: What have mast cells to do with edema formation, the consecutive repair and fibrinolysis? Int Arch Allergy Immunol 115: 2-8, 1998.

23. Scherber RM and Borate U: How we diagnose and treat systemic mastocytosis in adults. Br J Haematol 180: 11-23, 2018.

24. van der Weide HY, van Westerloo DJ and van den Bergh WM: Critical care management of systemic mastocytosis: When every wasp is a killer bee. Crit Care 19: 238, 2015.

25. Chen G, Chen L, Qin X, Xie X, Li G and Xu B: Systemic mastocytosis with recurrent anaphylactic shock and multiple organ dysfunction failure. Clin Lab 61: 179-182, 2015.

26. Chatterjee M, Sengupta S, Chakravartyr C, Ramasubban S, Bhartia S, Khan S and Agarwal VK: Indolent systemic mastocytosis manifesting as protracted anaphylactic shock. Indian J Crit Care Med 22: 311-313, 2018.

27. Kors JW, van Doormaal JJ and de Monchy JG: Anaphylactoid shock following Hymenoptera sting as a presenting symptom of systemic mastocytosis. J Intern Med 233: 255-258, 1993.
28. van Anrooij B, Oude Elberink JNG, Span LFR, de Monchy JGR, Rosati S, Mulder AB and Kluin-Nelemans JC: Midostaurin in patients with indolent systemic mastocytosis: An open-label phase 2 trial. J Allergy Clin Immunol 142: 1006-1008.e7, 2018.

29. Lortholary O, Chandesris MO, Bulai Livideanu C, Paul C, Guillet G, Jassem E, Niedoszytko M, Barete S, Verstovsek S, Grattan C, et al: Masitinib for treatment of severely symptomatic indolent systemic mastocytosis: A randomised, placebo-controlled, phase 3 study. Lancet 389: 612-620, 2017.

30. Hartmann K, Escribano L, Grattan C, Brockow K, Carter MC, Alvarez-Twose I, Matito A, Broesby-Olsen S, Siebenhaar F, Lange M, et al: Cutaneous manifestations in patients with mastocytosis: Consensus report of the European Competence Network on Mastocytosis; the American Academy of Allergy, Asthma \& Immunology; and the European Academy of Allergology and Clinical Immunology. J Allergy Clin Immunol 137: 35-45, 2016.

31. Valent $P$, Akin C, Hartmann K, Nilsson G, Reiter A, Hermine O, Sotlar K, Sperr WR, Escribano L, George TI, et al: Advances in the classification and treatment of mastocytosis: Current status and outlook toward the future. Cancer Res 77: 1261-1270, 2017.

32. Kristensen T, Vestergaard H and Møller MB: Improved detection of the KIT D816V mutation in patients with systemic mastocytosis using a quantitative and highly sensitive real-time qPCR assay. J Mol Diagn 13: 180-188, 2011.

33. Kayser S, Levis MJ and Schlenk RF: Midostaurin treatment in FLT3-mutated acute myeloid leukemia and systemic mastocytosis. Expert Rev Clin Pharmacol 10: 1177-1189, 2017.

34. Nakamura R, Chakrabarti S, Akin C, Robyn J, Bahceci E, Greene A, Childs R, Dunbar CE, Metcalfe DD and Barrett AJ: A pilot study of nonmyeloablative allogeneic hematopoietic stem cell transplant for advanced systemic mastocytosis. Bone Marrow Transplant 37: 353-358, 2006.

35. Ustun C, Reiter A, Scott BL, Nakamura R, Damaj G, Kreil S, Shanley R, Hogan WJ, Perales MA, Shore T, et al: Hematopoietic stem-cell transplantation for advanced systemic mastocytosis. J Clin Oncol 32: 3264-3274, 2014.

36. Theoharides TC, Valent $P$ and Akin C: Mast cells, mastocytosis, and related disorders. N Engl J Med 373: 163-172, 2015.

37. de Mol CL, Hermans MA, Gerth van Wijk R, van Hagen PM and van Daele PL: Routine abdominal ultrasonography has limited value in the care for patients with indolent systemic mastocytosis. Hematology 22: 544-547, 2017.

This work is licensed under a Creative Commons Attribution-NonCommercial-NoDerivatives 4.0 International (CC BY-NC-ND 4.0) License. 